\title{
Histórias de almas e milagres: a religião nos filmes silenciosos pernambucanos
}




\section{Resumo}

A produção cinematográfica pernambucana ao longo da década de 1920 inclui alguns títulos nos quais a religião tem especial relevância. Neste artigo, analisamos os filmes História de uma alma (Eustórgio Wanderley, 1926), Revezes... (Chagas Ribeiro, 1927) e Destino das rosas (Ary Severo, 1930), procurando compreender como neles se insere o elemento religioso, o porquê dessa recorrência e de que maneira está relacionada às particularidades do meio cinematográfico local, no que diz respeito à realização de filmes de enredo.

\section{Palavras-Chave}

Cinema Brasileiro, Cinema Silencioso, Religião, Pernambuco

\section{Abstract}

Film production in Pernambuco throughout the decade of 1920 includes some titles in which religion has particular relevance. This article analyses the films História de uma alma (Eustórgio Wanderley, 1926), Revezes... (Chagas Ribeiro, 1927) and Destino das rosas (Ary Severo, 1930), in order to understand how they deal with religious elements, the reason of this recurrence and in what way it is related to the singularities of the local film milieu, regarding fiction films production.

Key words

Brazilian Cinema, Silent Cinema, Religion, Pernambuco 
os anos 1920, a produção de filmes de ficção em Pernambuco começa por exibir marcada influência do cinema americano, trazendo para o cenário regional toda uma galeria de situações e personagens que caracterizavam os filmes de aventura e os populares seriados. A predominância de "americanismos" é ponto negativo que surge em alguns comentários publicados na imprensa local, a propósito da exibição dos primeiros filmes da produtora Aurora-Film, Retribuição e Jurando vingar, ambos lançados em 1925. Em uma época em que os parâmetros de refinamento e valor artístico continuavam a ser traçados a partir de modelos europeus e, em particular, franceses, a influência americana sobre os filmes locais só vinha confirmar a falta de status dessa produção, mais encarada enquanto entretenimento popular do que como criação artística relevante, destinada a públicos supostamente mais exigentes. Além disso, ao tomar o cinema americano como modelo, os filmes pernambucanos acabavam por reproduzir também algumas ousadias do American way of life, em franca contraposição aos costumes locais. É o que se pode observar no comentário do jornalista e teatrólogo Samuel Campello a respeito de Retribuição, reprovando a "imitação das fitas americanas [...] e até um casamento à americana, com declaração feita ao galã pela moça e logo após um passeio de automóvel" 1 .

Diante de tais restrições, os realizadores pernambucanos respondem com diferentes estratégias, entre elas a abordagem de temas e elementos religiosos. Na busca por ampliar tanto o seu público quanto seu reconhecimento na sociedade, a produção cinema-

1. Diário de Pernambuco, 22 mar 1925, p.4. 
tográfica pernambucana encontra na religião uma aliada de peso, capaz de legitimar os filmes enquanto produto cultural e artístico de valor e, ao mesmo tempo, fornecer uma abordagem de comprovado apelo comercial, junto a públicos de classes diversas. Pelo menos três filmes pernambucanos de ficção produzidos na década de 1920 trazem relevante teor religioso: História de uma alma (1926), Revezes... (1927) e Destino das rosas (1930). O material fílmico a que se tem acesso hoje é restrito. De História de uma alma restam apenas curtos fragmentos e alguns fotogramas, que se encontram no acervo da Cinemateca Brasileira, assim como a cópia em nitrato de Revezes..., completa embora bastante deteriorada. Destino das rosas é considerado um filme perdido. Não existem cópias ou sequer fragmentos.

Os três filmes vêm de diferentes produtoras, em momentos distintos da produção local. História de uma alma envolve a elite recifense em uma produção ambiciosa e amplamente divulgada que, junto com A filha do advogado (1926), caracteriza momento de aproximação entre burguesia e meio cinematográfico locais - figuras da "boa sociedade" comparecem nesses filmes, seja como investidores, intérpretes ou personagens. Lançado em 1927, quando já se nota um refluxo na realização de filmes de enredo, Revezes... se relaciona com as classes trabalhadoras não só na escolha do enredo regional protagonizado por vaqueiros e camponeses como também na extração social dos sócios fundadores da produtora Olinda-Film, "operários de oficinas gráficas dos nossos jornais da época", de acordo com Jota Soares (Cunha Filho, 2006, p.49).

Destino das rosas, da Spia-Film, tem à frente o então já experiente ator e diretor Ary Severo, integrante do núcleo inicial da Aurora-Film. Ao lado de No cenário da vida (1930), o filme marca a tentativa de se retomar a produção ficcional, interrompida desde 1927. Entretanto, diante do conturbado panorama político pós-Revolução de 1930, da consolidação do cinema sonoro e das dificuldades de exibição e profissionalização no mercado cinematográfico, o fôlego não vai longe. Os dois títulos serão os últimos filmes silenciosos de enredo produzidos no estado e exibidos em circuito comercial. 
Ao explorar o viés religioso, a produção pernambucana recorre a um filão que é dos primeiros a se consolidar na história do cinema, por meio das inúmeras Paixões de Cristo filmadas e exibidas sempre com grande concorrência de público. A julgar pelas informações das quais temos hoje conhecimento ${ }^{2}$, a produção brasileira do gênero tem início já na virada para a década de 1910 com Os milagres de Santo Antonio (Photo-Cinematographia Brasileira/Antonio Serra/Antonio Leal, 1909) e o cantante Os milagres de Nossa Senhora da Penha (William Auler/Alberto Botelho, 1910), cujas exibições eram acompanhadas por músicos e cantores atrás da tela. A produção posterior dará continuidade ao tema dos milagres de santos populares no país, a exemplo de Nossa Senhora da Aparecida e seus milagres (Mário Leite/Brasilgraph, 1919) e Os milagres de Nossa Senhora de Nazareth (Leo Marten, 1925).

A produção paulista investe no filão, embora existam informações desencontradas e uma boa parcela de indefinição quanto aos filmes que de fato chegaram a ser finalizados e exibidos. A essa dificuldade, vêm se juntar procedimentos comuns na época como o reaproveitamento de filmes anteriores e as mudanças de título ou mesmo de enredo no decorrer da produção, que embaralham ainda mais a tentativa de estabelecer uma filmografia precisa. Em 1916, Arturo Carrari teria realizado Os milagres de Nossa Senhora Aparecida - o que seu filho, José Carrari, desmente, em depoimento a Maria Rita Galvão (1975, p.240). Anos depois, o mesmo Carrari dirige Os milagres de Nossa Senhora da Penha (1923), que por sua vez terá trechos reaproveitados por Achille Tartari em Virgem da Penha e seus milagres (1930), com uma montagem diferente à qual foram acrescentadas novas cenas (Galvão, 1975, p.81). O interesse do público por filmes do gênero justificava tais manobras. Segundo Nicola Tartaglione, que trabalhou com Carrari na produção de 1923, “o filme era exibido com casas lotadas, rendeu um dinheiro grosso... Brasileiro é mesmo muito católico, não perde filme de religião, principalmente no interior" (Galvão, 1975, p.142).

2. Pesquisa realizada na base de dados Filmografia Brasileira (FB), elaborada pela Cinemateca Brasileira, disponivel em www.cinemateca.gov.br, acesso em: 21 jan 2008; e também em Galvão, Maria Rita (1975). 
Em meio à disputa por uma fatia desse mercado, os "filmes de religião" estrangeiros obrigavam os realizadores brasileiros a fazer malabarismos, como aconteceu com Francisco Madrigano. Quando já concluía um fịlme sobre a história de Santa Terezinha e seus milagres, foi surpreendido pela estréia de uma produção francesa com o mesmo tema. Prontamente, adaptou o enredo para a história de Nossa Senhora da Aparecida - "esta, pelo menos, é uma santa nacional, com ela não se corre o risco de ter de enfrentar concorrência estrangeira", justificou Madrigano (Galvão, 1975, p.57). E foi assim que $A$ rosa desfolhada ou Os milagres de Santa Terezinha acabou se tornando $O$ descrente (Francisco Madrigano,1927).

Talvez a produção francesa a que se refere Madrigano seja Vida de Santa Terezinha do Menino Jesus (Le rose effeuillée ou Un miracle de sainte Thérèse de l'Enfant Jésus, Georges Pallu, 1926), que em janeiro de 1927 está em cartaz no Rio de Janeiro. O comentário publicado nà revista Cinearte faz algumas restrições, mas observa que o filme "agradou extraordinariamente ao-público", tornando-se "um grande sucesso de bilheteria": ${ }^{3}$.

Meses antes da chegada do filme francês, porém, e provavelmente sem que se tivesse dele conhecimento, é lançado em setembro de 1926 no Recife o "filme sacro" História de uma alma. O enredo reconstitui a vida de Santa Teresa de Lisieux (1873-1897), adotando o mesmo título dos escritos autobiográficos da jovem carmelita, que fazia pouco havia sido canonizada pelo Vaticano, em 1925. É curioso perceber como nesse momento da produção pernambucana (1926) é acionada uma estratégia que remete ao movimento da indústria cinematográfica a partir de 1907 , quando procura adquirir maior respeitabilidade e, para tal, irá se valer de produções históricas, adaptações literárias e também filmes religiosos. No ensaio "Screen sermons: the uses of religion in early cinema after 1907" (Cosandey et al, 1992, p.187-96), Peter Krämer observa como a produção de filmes religiosos da Vitagraph seguia uma estratégia de marketing dirigida tanto ao público de uma classe média educada quanto às classes mais baixas - no primeiro caso pelo status

3. "A tela em revista". Cinearte, ano II, n.45, 05 jan 1927.

Significação $30 \cdot 30$ 
cultural das fontes e, no segundo, por sua popularidade. Os filmes bíblicos da Vitagraph enfatizavam os refinados valores da produção (cenários, figurinos) e faziam questão de garantir, nos anúncios publicitários, a fidelidade às fontes bíblicas, sendo que em relação a The life of Moses (1909-10) havia o destaque adicional de ter sido realizado sob a supervisão de um reverendo.

História de uma alma percorreu caminhos semelhantes. A sistemática divulgação na imprensa adotou o discurso da respeitabilidade, em que se entrelaçavam aspectos religiosos, econômicos e sociais. Afastando a idéia de precariedade, enfatizam o dinheiro investido na suntuosa produção. A distinção de classe fica por conta dos envolvidos na realização, todos membros de boa sociedade. A chancela moral, que afasta do filme a duvidosa reputação do meio cinematográfico, é dada pelo tema e pela aprovação da Igreja Católica. A escolha de tema religioso e a ligação com a Igreja Católica, que irá aprovar oficialmente a produção, não destoa em um meio bastante zeloso de sua religiosidade, no qual a Igreja tem papel expressivo e atuante, inclusive na imprensa, com as colunas regulares publicadas nos jornais ("Seção religiosa", no Jornal do Commercio, "Alma religiosa", no Diário de Pernambuco, por exemplo).

Como em diversas outras produções, brasileiras e estrangeiras, História de uma alma contará com o aval da Igreja e fará disso um tópico promocional. Submetido à aprovação das autoridades eclesiásticas, o projeto obtém um "elogioso parecer da Comissão de Arte Sacra da Arquidiocese" 4 . No filme, o Prólogo é "dedicado aos primeiros passos dados pela efetivação da formosa idéia de propaganda religiosa" s, quando aparece a fotografia do próprio arcebispo de Olinda e Recife, Dom Miguel Valverde, registrado no momento em que concede a licença para a produção sacra ${ }^{6}$.

Um importante diferencial de História de uma alma diz respeito à classe social das pessoas envolvidas em sua produção - outro ponto sempre reforçado na divulgação do filme. Boa parte dos

4. A Pilhéria, ano VII, n.258, 4 set 1926.

5. Oliveira, Waldemar de. "Vida artística". Jornal do Commercio, 19 set 1926, p.3.

6. É provável que se trate da mesma fotografia reproduzida em Cinearte, ilustrando o resumo do filme. Cf. Cinearte, ano II, n. 58, 06 abr 1927, p.6. 
envolvidos na realização cinematográfica em Pernambuco vinha das classes média e baixa, a exemplo do diretor Gentil Roiz e do cinegrafista Edison Chagas, fundadores da Aurora-Film, que exerciam a função de ourives antes de se dedicarem ao cinema. $O$ filme sacro, por sua vez, vai mobilizar nomes de famílias tradicionais da burguesia recifense, numa harmoniosa colaboração entre o clero e a elite. A imprensa respalda a iniciativa. História de uma alma recebe regular e expressivo espaço nos jornais e revistas, mais do que qualquer outra produção local da época. À notícia da criação da produtora Vera Cruz Film, seguem-se numerosas notas e matérias dando conta dos ensaios, preparativos, filmagens e lançamento do filme religioso.

Os primeiros ensaios são realizados no Cine Elite, mantido pela paróquia do tradicional bairro das Graças - nada mais adequado para uma produção envolvendo a boa sociedade católica recifense. $O$ entrosamento entre clero e elite se sobressai no longo artigo em duas partes que o padre Heliodoro Pires publica no Jornal do Commercio, pouco antes do lançamento de História de uma alma. Segundo ele, participam do filme um religioso carmelita, um religioso marista e duas irmãs de Caridade, além de serem mostrados retratos do arcebispo metropolitano e do vigário geral de Recife e Olinda ? Embora não deixe claro, ele é um dos religiosos a colaborar com o filme. No texto, destaca o trabalho das "matronas" d. Marietta Gomes de Mattos e d. Anna de Jesus Vergueiro da Silva, que "tomaram a seus ombros [...] a tarefa pesadíssima de preparar todas as roupas, dispor todos os cenários, fazer a maquiagem dos artistas...". Do filme participam sete filhos do casal Gesteira, incluindo a pequena Maria Pompéia Gesteira, de seis anos, que interpreta Santa Teresinha na infância. Dos 14 aos 25 anos, assume o papel Noemi Gomes de Mattos, que vem de uma família de "grandes paladinos das causas do catolicismo" no Brasil. Os maiores elogios são dispensados à menina Pompéia e ao diretor Eustórgio Wanderley, jornalista e professor reconhecido no meio cultural recifense, que em 1925 havia se tornado membro da Academia Pernambucana de Letras.

7. Jornal do Commercio, 18 e 19 ago 1926, p.3. As citações seguintes são desse texto.

Significação $30 \cdot 32$ 
$\mathrm{O}$ mesmo artigo traz informações que procuram respaldar a imagem de grande produção, criada em torno do filme. Para filmar as 280 cenas, que consumiram mais de 5 mil metros de película, foram investidos em torno de vinte contos de réis e mais de cem pessoas participaram da produção. Os custos teriam chegado a 25 contos, a julgar pelos dados divulgados na coluna do dramaturgo Waldemar de Oliveira, ele também colaborador, sendo um dos autores da partitura musical composta especialmente para o filme ${ }^{8}$. Ainda segundo Oliveira, as cenas "foram tiradas todas do natural, não havendo nenhuma onde fosse empregado o recurso do cenário". Isso significa que, apesar do prestígio, na prática a Vera Cruz Film não contava com um estúdio ou um espaço que viesse a cumprir essa função.

Sem estúdio e diante do desafio de recriar, em Recife, ambientes europeus do século XIX, partiu-se para adaptar construções locais às exigências do enredo. A principal locação parece ter sido o Colégio Estância, onde foram inclusive realizadas algumas tomadas internas, "fortemente iluminadas por projetores elétricos" " . Também serviram de cenário o claustro da Igreja da Misericórdia (representando a Abadia das Beneditinas, de Lixieux) e a portaria do convento de São Bento, ambos em Olinda, além da Estação Central e de residências cedidas por famílias da sociedade. As maiores despesas de História de uma alma devem ter ficado por conta da compra de filme virgem e dos trabalhos em laboratorio, incluindo ainda a confecção do figurino de época e os gastos com filmagem e equipe.

Os 20 ou 25 contos despendidos em História de uma alma ficam bem atrás de outra produção religiosa brasileira, o inacabado In hoc signo vinces (1921), dirigido por Almeida Fleming na cidade mineira de Pouso Alegre. O diretor afirma ter gastado cerca de 40 contos de réis na produção, sem nunca ter recuperado o investimento ${ }^{10}$. Segundo Alex Viany, o roteiro teria sido escrito com a colabo-

8. Oliveira, Waldemar de. "Vida artística". Jomal do Commercio, 19 set 1926, p.3. A citação seguinte é desse texto.

9. Jornal do Commercio, 20 abr 1926, p.8. A citação seguinte é desse texto.

10. Filmografia Brasileira. Site www.cinemateca.gov.br, acesso em 21 jan 2008, às 15 hoo. 
ração de padres locais, enquanto os dispendiosos cenários seriam "evidentemente inspirados nos opulentos dramas pseudo-históricos que os italianos fabricavam naquela época" (Viany, 1987, p.63).

Entre as ficções pernambucanas do período, o filme da elite católica também não terá sido o mais dispendioso. Produzido no mesmo ano pela Aurora-Film, então comandada pelo bem-sucedido comerciante João Pedrosa da Fonseca, A filha do advogado teria custado 35 contos, salto considerável em relação às primeiras produções da Aurora, Retribuição (5 contos) e Jurando vingar (7 contos). Essas não são quantias divulgadas na Época, e sim relatadas por Jota Soares décadas.depois (Apud. Behar, 2002, p.187). Mesmo levando em conta as armadilhas da memória (e das idealizações), que podem ter alterado alguns contos de réis nos orçamentos reais, não se pode duvidar da alta aposta representada pelas duas maiores produções pernambucanas do período silencioso, História de uma alma e A filha do advogado, não só em termos de orçamento como também - inseparável dos custos - de empenho no sentido de alcançar reconhecimento artístico, comercial e social.

A longa duração de História de uma alma, com dezesseis partes e mais o Prólogo, faz com que seja separado, na exibição, entre $1^{a}$ e $2^{a}$ épocas. Nos periódicos locais, as resenhas em geral não ultrapassam as considerações gerais e elogios protocolares, destacando sempre o grande sucesso de público. Comentário mais extenso é publicado no Jornal Pequeno e reproduzido em Cinearte. Vem assinado por dr. Corrêa Neto, "lente do Ginásio Pernambucano e advogado de crédito", que se desdobra em louvores à produção e ao elenco, deixando de lado julgamentos mais severos: "Não quero afirmar entretanto que seja um trabalho artisticamente inatacável; porém, todos hão de concordar em que há cenas de uma realidade e naturalidade incomparáveis; cenas que enternecem, que edificam, que impressionam, que comovem ate" " caracteriza o texto publicado na revista recifense $A$ Pilhéria: o filme, que "causou a mais viva impressão", "tem movimentos de técnica exemplares e se desdobra em cenários e interiores de curiosa

11. Lima, Pedro. "Filmagem brasileira". Cinearte, ano II, n. 57, 20 mar 1927, p.5 e 35. 
beleza, conduzindo o espectador, até a última cena, em viva simpatia" ${ }^{2}$.

As considerações mais críticas sobre o filme, que mal chegam à imprensa, soam mais convincentes do que os elogios. Em Cinearte, Mário Mendonça define História de uma alma como "fillme histórico sem convicção, demasiado longo, cacete e repleto de senões" ${ }^{13}$. Correspondente da revista em Recife, Mendonça permanece durante bom tempo como a principal fonte sobre a movimentação cinematográfica na cidade, enviando regularmente notícias para a coluna sobre cinema brasileiro, mantida por Adhemar Gonzaga e Pedro Lima. Em carta a Gonzaga, Mendonça será ainda mais impaciente e implacável com História de uma alma. Para ele, trata-se de "um filme ridículo, não só porque não tem a convicção necessária, como pelos inúmeros disparates que aparecem", como "postes da Tramways, fios elétricos, reclames do.Tractor Fordson, almofadinhas, mamoeiros etc", em uma história que se passa no século $\mathrm{XIX}^{14}$. Aponta também a "ausência completa de vestuários da época" e a "fotografia ruim", para concluir que a Vera Cruz "precisa de gente que entenda melhor o cinema".

Décadas depois, o diretor e ator Ary Severo viria a comentar o filme em termos semelhantes, considerando-o "maçante", muito longo, com "muitas cenas paradas" e sem variação de planos (Apud. Behar, 2002, p.118-9). As observações de Severo e Mendonça põem a descoberto não só as dificuldades de produção como a falta de habilidade em termos de linguagem e de condução do enredo, o que permite vislumbrar História de uma alma como uma peculiar combinação entre pompa e precariedade, ambição e despreparo.

As poucas imagens que restaram do filme não são suficientes para confirmar tal impressão, mas podem dar algumas pistas ${ }^{15}$.

12. A Pilhéria, ano VIII, n.261, 25 set 1926.

13. Mendonça, Mário. "A propósito de um filme - Novas fábricas", nota publicada em Lima, Pedro. "Filmagem brasileira". Cinearte, ano II, n. 61, 27 abr 1927, p.4-5.

14. Carta de Mário Mendonça a Adhemar Gonzaga. Recife, 26 out 1926. As citações seguintes sāo dessa carta.

15. Material examinado em mesa enroladeira, na Cinemateca Brasileira, em 12 jan 2007. Características: cópia $35 \mathrm{~mm}$ em nitrato, preto e branco, 6 rolos pequenos no total de 75 metros. 
Um pequeno fragmento mostra a conversa de um religioso com um homem de barba longa, portando um cajado. É uma cena interna, um pouco escura, que pode corresponder à visita do pai de Santa Teresinha, quando ainda solteiro, ao mosteiro de São Bernardo, para "pedir a graça de se fazer,monge", o que the é negado ${ }^{16}$. Ou, ainda, levando em conta a aparência do visitante, pode se tratar do "Mendigo" relacionado na lista de personagens. No plano em que o homem e o religioso conversam sentados e, em seguida, se levantam; existe certo desajeito no enquadramento. No início, as duas figuras só ocupam a metade inferior do quadro, deixando vazia a metade superior. É só quando se levantam que se estabelece uma composição mais equilibrada. Aqui talvez se encontre um breve exemplo da pouca intimidade dos realizadores com a linguagem cinematográfica, embora mesmo profissionais experientes da época costumassem incorrer em problemas semelhantes.

Os ambiẹntes dos planos existentes são despojados, o que se explica pelas limitações de produção mas também parece ser um recurso para não arrisçar comprometer a reconstituição de época com elementos impróprios ao tempo e aos lugares da história. Pouces: móveis compõem tanto a sala onde o visitante conversa com o religioso quanto o interior do quarto da noviça, no qual ela será tentada pelo demônio, como se vê em fotografia publicada em Cinearte, junto com o resumo do filme. Em outros fragmentos, temos planos externos de um jardim, em que se destaca um caramanchão. A jovem Teresa aparece com a cabeça enfaixada e enxuga as lágrimas com um lenço. Isolada das outras meninas, ela está sentada ao lado de uma freira, que a consola. A cena se ajusta a um relàto de filmagem, noticiado em: $A$ Pilhéria: "foram apanhadas belíssimas cenas no claustro da Igreja da Misericórdia em Olinda, onde Santa Teresinha menina estava rodeada de diversas colegas de colégio na Abadia das Beneditinas" "17. Culminando a sequiência, deveria acontecēr a cura da doença, entrando o intertítulo: "Milagre! Estou curada de minha

16. "Historia de uma alma" [resumo do filme]. Cinearte, ano II, n. 58, 06 abr 1927, p.6.

17. A Pilhéria, ano ViI, n.251, 17 jul 1926.

Significação $30 \cdot 36$ 
dolorida cabeça!". Esse é um dos intertítulos ainda existentes, que traz a numeração 219. Apenas outro é também numerado, justamente o seguinte, de número 220 , onde se lê o nome e endereço da produtora. Como ainda estamos no meio da história, é possível que seja aqui o final da primeira época, encerrada com a cura milagrosa.

Nos filmes silenciosos brasileiros, a numeração dos intertítulos nem sempre obedece a uma ordenação lógica. No caso de História de uma alma, talvez os números dos intertítulos encontrados identifiquem as diferentes cenas, que chegariam a 280 , segundo o artigo do padre Heliodoro Pires. Os poucos intertítulos que sobraram incluem falas de diálogo, uma carta enviada ao pai de Teresa e o que parece ser uma transcrição do livro História de uma alma, reunião dos escritos da futura Santa Teresa de Lisieux: "E aquela ligeira barquinha é meu coração que não afastarei jamais do olhar de Jesus para que veleje em paz e rapidamente em demanda das praias celestes". O grande número de cenas, assim como as características dos intertítulos existentes, sugerem um trabalho de adaptação disposto não à síntese mas ao acúmulo de acontecimentos narrados por Teresa, talvez com o objetivo de exibir maior fidelidade ao relato original, reforçando assim a seriedade do projeto - o filme enquanto fiel transposição do livro.

Entre os filmes silenciosos pernambucanos, História de uma alma é o que apresenta temática religiosa mais evidente, encaixandose à perfeição na categoria de "filme sacro". No entanto, também Revezes... e Destino das rosas, produções mais modestas, incorporam elementos religiosos em seus enredos. Além desses, e apesar da escassez de informações, é possível detectar um breve momento religioso mesmo na trama tão mundana de No cenário da vida. Segundo depoimento do ator Claudio Celso (pseudônimo de Manoel Coelho), o protagonista interpretado por ele consegue sobreviver à fuga do presídio de Fernando de Noronha graças à aparição de uma santa: desmaiado na jangada depois do esforço em escapar da ilha, ele se recupera quando a santa aparece e lhe abre os braços, reanimando-o ${ }^{18}$.

18. Apud. A última diva (2007), documentário dirigido por Nelson Sampaio, Fernando Victorino e Virginia Carvalho. 
A sinópse de Revezes... na Filmografia Brasileira e mesmo o resumo püblicado em $A$ Pilhéria, ainda dúrante a etapa de produção ${ }^{19}$, não deixam entrever nenhum traço de religião, mas o exame das imagens do filme aponta uma recorrência tanto à iconografia quanto ao sentimento religioso, já quando a história se encaminha para o desenlace ${ }^{20}$.

O filme é ambientado na fazenda de gado Esperança, "vulgarmente conhecida como a "Fazenda dos Suplícios", pelos "contínuos feitos de desumanidade que ali se praticam", explica o intertítulo. A intriga começa por enfatizar o vilanismo do proprietário, Jacyntho, que já nas̉ primeiras cenàs ordena a seus empregados que castiguem cruelmente üm ladrão de gado, capturado durante a fuga. Em contraposição à tirania de Jacyntho, destaca-se a amizade entre dois vaqueiros, unidos ainda mais pelo namoro entre seus filhos, Carlos e Celia. O triângulo amoroso - e estopim dramático da trama - se completa com o fillho do patrão, Jayme, igualmente déspota, que tenta conquistar o amor da mocinha, sendo por ela sempre rejeitado. Ao conflito romântico, soma-se a situação de iminente decadência dả fazenda, com a febre aftosa dizimando o gado, e a discussão entre o patrão e os vaqueiros que exigem seus salários atrasados. A revolta dos empregados aumenta quando Jayme, de tocaia, atira em Carlos, cuja morte desencadeia dois embates. De um lado, acompanhamos o conflito entre o grupo de vaqueiros e Jacyntho: depois de uma aćirrada briga, o patrão é subjugado, mas não morto - terminará seus dias pedindo esmolas. De outro, existe a vingança do irmão dè Carlos, que persegue e mata Jayme:

O encaminhamento final, no entanto, deixa de lado a aventura para investir num desfecho marcado pela religiosidade. Com a morte de Carlos, Celia adoece e vai definhando. No quarto onde fica prostrada na cama, existe uma gravura de Jesus Cristo na parede e

19. A sinopse da FB reproduz informações de BERNARDET (1971); o resumo do filme está em A Pilhéria, ano VIII, n.263, 9 out 1926.

20. Material examinado em mesa enroladeira, na Cinemateca Brasileira, em 12 de fevereiro de 2004. Características: cópia $35 \mathrm{~mm}$ em nitrato, preto e branco com tingimento, 6 rolos, no total de $1.210 \mathrm{~m}$. Material bastante danificado, com hidrólise seca em todos os rolos. 
um oratório sobre a mesa. Certo dia ela deixa o quarto, não sem antes rezar diante do oratório, e vai até a sepultura do amado. Ajoelhada ao lado da cruz, vê o espectro de Carlos. Em fusão, ele surge de túnica branca, estendendo os braços em sua direção. Ela se levanta e abre os braços em cruz. O vulto desaparece, Celia cai deitada sobre a sepultura - "Morta!", confirma o intertítulo. Ao encontrála, a mãe se joga sobre o corpo da filha, enquanto os dois vaqueiros amigos, de pé, tiram o chapéu diante da cena, em uma composição que remete ao "Angelus", de Jean-François Millet, quadro largamente reproduzido em gravuras e folhinhas religiosas. Em seguida, enquanto o corpo da moça $e$ carregado, surgem em superposição os vultos de Carlos e Celia, ambos vestindo túnicas brancas. Aos poucos, seus vultos começam a desaparecer, diminuindo de tamanho, se confundindo com o branco das nuvens. Eles sobem ao céu, literalmente. Em Revezes..., o triângulo amoroso e o interessantíssimo conflito de classes vão a segundo plano nesse desenlace, no qual o melodrama recebe a bênção celestial. A mocinha morre de amor e o par romântico encontra a merecida felicidade na vida eterna.

Vale chamar a atenção aqui para esse atrativo adicional dos filmes de conotações religiosas: os efeitos especiais. Se desde a década de 1960 a cidade-teatro de Nova Jerusalém, no interior de Pernambuco, atrai grande público para as apresentações anuais de sua Paixão de Cristo, com uma parafernália visual e sonora cada vez mais elaborada, já os filmes silenciosos pernambucanos, ainda que em escala mais modesta, não deixavam de procurar agradar os espectadores com efeitos de câmera e truques de laboratório. Em $R e$ vezes..., as superposições colocam no mesmo plano desejo e realidade, vida terrena e espiritual. História de uma alma também não deve ter dispensado os efeitos, talvez quando Teresa aprende a soletrar e vê "uma noite no céu a letra inicial do seu nome" ou, ainda mais provável, na aparição de Lúcifer, com o figurino de um demônio de teatro burlesco ou dos filmes de Méliès. Os efeitos tinham o poder de fascinar não só o público mas também os próprios realizadores. Nicola Tartaglione se entusiasma ao lembrar a realização de $O s$ milagres de Nossa Senhora da Penha: "Que filme interessante!... Tinha truques formidáveis, que faziam os espectadores tremerem de 
emoção e suspense. Cenas inteiras montadas quadro por quadro, imagens superpostas, uma trabalheira sem fim. Mas valeu a pena" (Galvão, 1975, p.142).

Sem serem propriamente "filmes de religião", Revezes... e, ao que tudo indica, Destino das rosas são melodramas que reforçam a dualidade entre bem e mal por meio do sentimento religioso que move - e recompensa, embora não necessariamente em vida os personagens bons. Não existem mais cópias de Destino das rosas e as informações sobre o enredo são poucas. A partir de depoimentos de Dustan Maciel e Pedro Neves, ambos do elenco, Lucilla Bernardet (1970, p.113-4) chegou a uma sinopse resumida e, curiosamente, não muito diferente da história de Revezes... Também ambientado em uma fazenda, Destino das rosas tem como centro as desventuras amorosas da filha de um colono, apaixonada pelo filho do fazendeiro, estudante na capital, e de Carrapiche, cujo amor pela moça não é correspondido. Rapaz modesto, com o estigma de um defeito físico (é manco), Carrapiche descobre as más intenções do estudante. Quando ela toma conhecimento de que o moço rico só deseja seduzi-la e nada mais, sofre um choque emocional e adoece gravemente. Sem dinheiro para comprar flores, Carrapiche rouba as rosas de Nossa Senhora para dar de presente à moça. Em seguida, mata o estudante com uma espingarda. No final, Carrapiche vai preso, a jovem morre e ele parte em busca de vingança. Nessa șinopse, o desfecho não parece coerente. Afinal, depois de matar o rival qual serria a vingança de Carrapiche? É de se supor, pela lógica dramática, que as ações seguisssem outra ordem: primeiro, Carrapiche seria preso pelo roubo das flores e, ao saber da morte da moça, partiria em busca de vingança, matando aquele que, indiretamente, a matou. Essa, entretanto, é a nossa visão atual do que seja "lógica dramática", que está longe de ser a dominante nas ficções silenciosas brasileiras.

A propósito de Revezes... (cuja heroína teria morrido de tuberculose, segundo Jota Soares) e Destino das rosas, Lucilla Bernardet observa: "da tuberculose ao aleijão, o cinema pernambucano vai caindo em um romantismo doentio" (Bernardet, 1970, p.114). Na época, o que se destaca na imprensa local em relação aos dois filmes é o regionalismo. Revezes... é divulgada como 
uma "novela regional" "21, apresentando "muitas passagens do nosso hinterland" "22, que aborda "motivos da vida do nosso rude caboclo", com a ação se passando "principalmente no nosso sertão, com o jogo de fortes cenas da sua vida típica, no seu viver natural e simples. É um poema da vida do nosso homem do mato" ${ }^{23}$.

O aspecto regional de Destino das rosas é especialmente enfatizado, tanto mais porque serve como uma espécie de trunfo e diferencial para o filme, em meio às comparações que se estabelecem. O enredo é inspirado na peça As rosas de Nossa Senhora, de Manuel Matos, que por coincidência também estava sendo adaptada nessa mesma época pela produtora paulista Astro Film. "Pernambucanos versus paulistas...", provoca o crítico de cinema Nehemias Gueiros ${ }^{24}$. Um dos sócios da Spia-Film, produtora de Destino das rosas, Luis Maranhão escreve a Pedro Lima explicando as mudanças na concepção do filme em relação à peça e ao filme paulista:

Reputamos um absurdo filmar num ambiente português um assunto que é originariamente espanhol [como faz a produção paulista], só porque a peça teatral mais conhecida é uma adaptação lusitana. Sendo um motivo regional, preferimos adapta-lo cinematograficamente ao nosso meio a filmá-lo num falso ambiente estrangeiro, cheio de teatralidade.

Para afastar toda a teatralidade do nosso Destino das rosas, escrevi o enredo em forma de conto regional brasileiro e entreguei-o ao Ary Severo que o cenarizou com critério.

Cortamos a descrição do roubo das rosas com aquela visão de santos a desembainhar espadas [...] Numa publicação dum jornal de São Paulo, o noticiarista disse que no filme da Astro tomaram parte tantos artistas $e$

21. Jomal do Commercio, 19 dez 1926, p.3.

22. Jornal do Commercio, 13 mar 1927, p.6.

23. A Pilhéria, ano VIII, n.260, 18 set 1926.

24. "Cinematographia". Jornal do Commercio, 12 jan 1930, p.10. 
tantas girls. Isto de girls èm fita está cheirando muito a coro de companhia de revista. Até o títùlo modificamos, pois achamos Rosas de $N$ :Senhora muito próprio para filme sacro; embora isto nos servisse de reclame ${ }^{25}$.

Diante da ausência de cópias e das poucas informações sobre o enredo, é difícil definir até que ponto Destino das rosas explora élementos religiosos. De qualquer maneira, mesmo com título e enredo modificados, a relação com a peça As rosas de Nosía Senhora é sempre lembrada nà divulgação do filme, o que indiretamente acaba por lhe servir de "reclame". Ofilme não deixa de tirar proveito da grande popularidade da peça, "que a Cia Leopoldo Froes levou tantas vezes em nossos teatros", como destaca o anúncio da Astro Film: (Galvão, 1975, p.323), sendo encenada também nos picadeiros: Em novembro de 1925 , por exemplo, é uma das atrações do Circo Dudu, em Recife.

A presença, em Destino das rosas, de um personagem como Carrapiche, que exigiu do ator Pedro Neves especial caracterização para interpretar o rapaz aleijado; permite especular sobre outro viés religioso trabalhado no filme, agora dentro de um diálogo não com espetáculos teatrais e circenses mas com o cinema. Mais precisamente, com os filmes estrelados por Lon Chaney, um dos artistas mais célebres do período silencioso, conhecido como "o homem das mil faces" por suas notáveis caracterizações. Entre seus inúmeros admiradores, contava-se o diretor e ator Jota Soares; um dos principais nomes da produção pernambucana do período, que iria imitar o astro americano em duas sessões de fotos; em 1926 e 1927, reproduzindo sob pesada maquiagem caracterizações do ator em $O$ corcunda de Notre Dame (The hunchback of Notre Dame, Wallace Worsley, 1923) e O fantasma da ópera.(The phantom of the Opera, Rupert Julian, 1925). Chaney também deveria exercer grande fascínio sobre Pedro Neves, notório transformista e imitador, que já havia criado um tipo a la Buster Keaton na comédia Herói do século XX (Ary Severo, 1926).

25. Carta de Luis Maranhão a Pedro Lima. Recife, 9 fev 1930.

Significação $30 \cdot 42$ 
Em filmes hoje pouco conhecidos como Penalty. (Wallace Worsley, 1920), The shock (Lambert Hillyer, 1923), Shadows (Tom Forman, .1923) e The road to Mandalay (Tod Browning, 19.26), o caráter de aventura e exotismo vem combinado ao melodrama, cuja moralidade final se dá em termos marcadamente religiosos: Os personagens excêntricos, vilanescos e mesmo desagradáveis encarnados por Chaney terminam por alcançar a redenção moral. $\mathrm{O}$ que se vê na tela são verdadeiras conversões. Embora não sejam os galãs da história, seus personageṇs quase sempre se impõem como os verdadeiros heróis. E é essa lógica que parece embasar a construção de um personagem como Carrapiche, uma aposta do filme para estabelecer comunicação junto a um público já acostumado, e irrestrito admirador, dos tipos criados por Chaney: Carrapiche, que não é vilão mas carrega o estigma de um defeito físico, mostra-se mais valoroso do que o suposto galã e acaba por se converter no herói de Destino das rosas - é esse estatuto de herói que explica a declaração do próprio Pedro Neves, ao afirmar, vaidoso, que seu personagem era o "galã do filme" (Bernardet, 1970, p.114).

A vida de uma santa como tema (História de uma alma) ou a religião como substrato para o embate entre o bem e o mal (Revezes... e Destino das rosas) apontam uma inclinação se não dominante certamente significativa entre as ficções pernambucanas do período silencioso. Como compreender essa recorrência? No terreno das influências cinematográficas, a abordagem religiosa significa uma resposta às críticas de "americanismo", acionando um repertório diferente que não o do cinema hollywoodiano em sua vertente mais popular, comercial e, para muitos de gosto cultivado, vulgar - e aqui não estariam incluídas as produções "de qualidade" estreladas por Lon Chaney. Tal distanciamento é reforçado pelo tratamento regionalista (em Revezes... e Destino das rosas) ou mesmo, no outro extremo, pela escolha de tema e ambientes europeus (História de uma alma), reverenciando assim a referência maior em termos de refinamento cultural e qualidade artística.

Em uma perspectiva mais ampla, é possível pensar que aí existe também um movimento no sentido de reafirmar valores tradicionais e estáveis, reagindo a toda uma série de transformações e 
tensões pelas quais passava o Recife da década de 1920. Entre a instabilidade político-econômica e a permanência das elites históricas, a cidade assiste ao surgimento de uma nova fisionomia urbana, de novas práticas sociais, novos costumes - ou, pelo menos, instalase o desejo por tantas novidades, nem sempre concretizadas. E entre as transformações estava o próprio cinema: as novidades trazidas pelos filmes (e eventualmente imitadas pelos espectadores); a crescente mundanidade da qual fazia parte frequientar, ver e ser visto nas salas de cinema; e a existência de uma produção cinematográfica, que apesar dos impasses e dificuldades enfrentados, significava uma considerável conquista moderna, fazendo com que a cidade passasse de consumidora a produtora de imagens próprias, tanto documentais quanto de ficção. Toda essa modernidade em torno do cinema parece demandar, como contraponto e fator de equilíbrio, um investimento igualmente considerável na tradição e em valores há muito estabelecidos.

Também não se deve perder de vista que, para além da busca por reconhecimento social, cultural e artístico, a recorrência a elementos religiosos representa uma das principais apostas para viabilizar o projeto comercial - e portanto, a continuidade - da produção de enredo local. O desafio da profissionalização é uma constante desde Retribuição até Destino das rosas; atravessa, imperturbável e sem nunca se concretizar satisfatoriamente tanto os períodos de atividade mais intensa quanto os momentos de "marasmo" (para usar o termo tão ao gosto de Adhemar Gonzaga e Pedro Lima). Daí o apelo religioso surgir em filmes separados no tempo, na origem de produção, no projeto cinematográfico. Em comum, existe a perspectiva de comunicação com o público. Além disso, é uma maneira da incipiente e precária atividade cinematográfica local se fortalecer. Na falta de tradição própria, alinha-se a gêneros e formas de entretenimento amplamente reconhecidos - melodrama religioso, filme sacro, teatro popular, circo, apresentações de rua. Afirma-se enquanto espetáculo.

Legitimação artística, cultural e social. Conquista de público. Profissionalização. Para o cinema silencioso pernambucano alcançar tantas graças, só mesmo apelando aos santos e seus milagres. 


\section{Bibliografia}

BEHAR, Regina Maria Rodrigues. "Caçadores de imagem": cinema e memória em Pernambuco. São Paulo: Tese de Doutorado, ECA/USP, 2002.

BERNARDET, Lucilla Ribeiro. O cinema pernambucano de 1922 a 1931: primeira abordagem. São Paulo, 1970.

. Retrospectiva n.13. Cinemateca do Museu de Arte Moderna/Clube de Cinema do Rio de Janeiro/Secretaria de Turismo do Governo da Guanabara, 1971.

CUNHA FILHO, Paulo C. (org.). Relembrando o cinema pernambucano - Dos Arquivos de Jota Soares. Recife: Fundação Joaquim Nabuco/Editora Massangana, 2006.

GALVÃO, Maria Rita. Crônica do cinema paulistano. São Paulo: Ática, 1975.

KRÄMER, Peter. "Screen sermons: the uses of religion in early cinema after 1907". In: COSANDEY, Roland; GAUDREAULT, André; GUNNING Tom (dir.). Une invention du diable? Cinéma des premiers temps et religion. Sainte-Foy/Lausanne, Les Presses de l'Université Laval/Edition Payot Lausanne, 1992, p.18796.

RAMOS, Fernão e MIRANDA, Luiz Felipe (orgs). Enciclopédia do cinema brasileiro. São Paulo: Senac, 2000.

VIANY, Alex. Introdução ao cinema brasileiro. Rio de Janeiro: Alhambra/Embrafilme, 1987.

\section{Inédito}

ARAÚJO, Luciana Corrêa de. Aspectos do cinema em Recife nos anos 1920. São Paulo: Relatório de Pós-Doutorado/Bolsa Fapesp, 2005.

\section{Periódicos}

Cinearte (Rio de Janeiro). Também disponível em: http:// www.bjksdigital.museusegall.org.br

Diário de Pernambuco (Recife) 
Jornal do Commercio (Recife)

A Província (Recife)

\section{Site}

www.cinemateca.gov.br

\section{FILMOGRAFIA BÁSICA}

DESTINO DAS ROSAS 1930. Ary Severo. Recife, PE: Spia-Film. 6 partes: silencioso, $\mathrm{p} / \mathrm{b}, 35 \mathrm{~mm}$.

"A FILHA DO ÄDV̈OGADO. 1926. Jota Soares. Recife, PE: Aurora-Film. 11 partes: silencioso, $\mathrm{p} / \mathrm{b}, 35 \mathrm{~mm}$.

HISTÓRIA DE UMA ALMA. 1926. Eustórgio Wanderley. Recife, PE: Vera Cruz-Film. 16 partes e Prólogo: silencioso, p/b, 35mm.

JURANDO VINGAR. 1925. Ary Severo. Recife, PE: Aurora-Film. 6 partes: silencioso, $\mathrm{p} / \mathrm{b}, 35 \mathrm{~mm}$.

NO CENÁRIO DA VIDA. 1930. Luis Maranhão e Jota Soares. Recife, PE: Liberdade-Film. 6 partes: silencioso, p/b, 35mm.

RETRIBUIÇÃO. 1925. Gentil Roiz. Recife, PE: Aurora-Film. 6 partes: silencioso, $\mathrm{p} / \mathrm{b}, 35 \mathrm{~mm}$.

REVEZES... . 1927. Chagas Ribeiro. Recife, PE: Olinda-Film. 7 partes: silencioso, $\mathrm{p} / \mathrm{b}, 35 \mathrm{~mm}$. 